\title{
An Iterative Algorithm for the Split Equality and Multiple-Sets Split Equality Problem
}

\author{
Luoyi Shi, ${ }^{1}$ Ru Dong Chen, ${ }^{1}$ and Yu Jing Wu ${ }^{2}$ \\ ${ }^{1}$ Department of Mathematics, Tianjin Polytechnic University, Tianjin 300387, China \\ ${ }^{2}$ Tianjin Vocational Institute, Tianjin 300410, China
}

Correspondence should be addressed to Ru Dong Chen; chenrd@tjpu.edu.cn

Received 11 December 2013; Revised 8 February 2014; Accepted 10 February 2014; Published 13 March 2014

Academic Editor: Yisheng Song

Copyright (C) 2014 Luoyi Shi et al. This is an open access article distributed under the Creative Commons Attribution License, which permits unrestricted use, distribution, and reproduction in any medium, provided the original work is properly cited.

The multiple-sets split equality problem (MSSEP) requires finding a point $x \in \cap_{i=1}^{N} C_{i}, y \in \cap_{j=1}^{M} Q_{j}$ such that $A x=B y$, where $N$ and $M$ are positive integers, $\left\{C_{1}, C_{2}, \ldots, C_{N}\right\}$ and $\left\{Q_{1}, Q_{2}, \ldots, Q_{M}\right\}$ are closed convex subsets of Hilbert spaces $H_{1}, H_{2}$, respectively, and $A: H_{1} \rightarrow H_{3}, B: H_{2} \rightarrow H_{3}$ are two bounded linear operators. When $N=M=1$, the MSSEP is called the split equality problem (SEP). If $B=I$, then the MSSEP and SEP reduce to the well-known multiple-sets split feasibility problem (MSSFP) and split feasibility problem (SFP), respectively. One of the purposes of this paper is to introduce an iterative algorithm to solve the SEP and MSSEP in the framework of infinite-dimensional Hilbert spaces under some more mild conditions for the iterative coefficient.

\section{Introduction and Preliminaries}

1.1. Introduction. Let $\left\{C_{1}, C_{2}, \ldots, C_{N}\right\}$ and $\left\{Q_{1}, Q_{2}, \ldots, Q_{M}\right\}$ be nonempty closed convex subsets of real Hilbert spaces $H_{1}$ and $H_{2}$, respectively, and let $A: H_{1} \rightarrow H_{2}$ be a bounded linear operator. The multiple-sets split feasibility problem (MSSFP) is to find a point $x$ satisfying the property:

$$
x \in \bigcap_{i=1}^{N} C_{i}, \quad A x \in \bigcap_{j=1}^{M} Q_{j},
$$

if such point exists. If $N=M=1$, then the MSSFP reduce to the well-known split feasibility problem (SFP).

The SFP and MSSFP were first introduced by Censor and Elfving [1] and Censor et al. [2], respectively, which attract many authors' attention due to its applications in signal processing [1] and intensity-modulated radiation therapy [2]. Various algorithms have been invented to solve it; see [1-8], e.t.

Recently, Moudafi [9] propose a new split equality problem (SEP): let $H_{1}, H_{2}$, and $H_{3}$ be real Hilbert spaces; let $C \subseteq H_{1}, Q \subseteq H_{2}$ be two nonempty closed convex sets; and let $A: H_{1} \rightarrow H_{3}, B: H_{2} \rightarrow H_{3}$ be two bounded linear operators. Find $x \in C, y \in Q$ satisfying

$$
A x=B y .
$$

When $B=I$, SEP reduces to the well-known SFP.

Naturally, we propose the following multiple-sets split equality problem (MSSEP) requiring to find a point $x \in$ $\cap_{i=1}^{N} C_{i}, y \in \cap_{j=1}^{M} Q_{j}$ such that

$$
A x=B y,
$$

where $N$ and $M$ are positive integers; $\left\{C_{1}, C_{2}, \ldots, C_{N}\right\}$ and $\left\{Q_{1}, Q_{2}, \ldots, Q_{M}\right\}$ are closed convex subsets of Hilbert spaces $H_{1}, H_{2}$, respectively, and $A: H_{1} \rightarrow H_{3}, B: H_{2} \rightarrow H_{3}$ are two bounded linear operators.

In the paper [9], Moudafi gave an alternating CQalgorithm and relaxed alternating CQ-algorithm iterative algorithm for solving the split equality problem.

We use $\Gamma$ to denote the solution set of SEP, that is,

$$
\Gamma=\left\{(x, y) \in H_{1} \times H_{2}, A x=B y, x \in C, y \in Q\right\},
$$

and assume consistency of SEP so that $\Gamma$ is closed, convex, and nonempty. 
Let $S=C \times Q$ in $H=H_{1} \times H_{2}$ and define $G: H \rightarrow H_{3}$ by $G=[A,-B]$; then $G^{*} G: H \rightarrow H$ has the matrix form

$$
G^{*} G=\left[\begin{array}{cc}
A^{*} A & -A^{*} B \\
-B^{*} A & B^{*} B
\end{array}\right] .
$$

The SEP problem can be reformulated as finding $w=(x, y) \epsilon$ $S$ with $G w=0$ or solving the following minimization problem:

$$
\min _{w \in S} f(w)=\frac{1}{2}\|G w\|^{2}
$$

In paper [10], we used the well-known Tychonov regularization that got some algorithms to converge strongly to the minimum-norm solution of the SEP.

Note that the convergence of the above algorithms depends on the exact requirements of the iterative coefficient. Therefore, the aim of this paper is to introduce an iterative algorithm to solve the SEP and MSSEP in the framework of infinite-dimensional Hilbert spaces under some more mild conditions for the iterative coefficient.

Throughout the rest of this paper, $I$ denotes the identity operator on Hilbert space $H$ and $\operatorname{Fix}(T)$ is the set of the fixed points of an operator $T$. An operator $T$ on a Hilbert space $H$ is nonexpansive if, for each $x$ and $y$ in $H,\|T x-T y\| \leq$ $\|x-y\| . T$ is said to be averaged, if there exists $0<\alpha<1$ and a nonexpansive operator $N$ such that $T=(1-\alpha) I+\alpha N$.

Let $P_{S}$ denote the projection from $H$ onto a nonempty closed convex subset $S$ of $H$; that is,

$$
P_{S}(w)=\min _{x \in S}\|x-w\| .
$$

It is well known that $P_{S}(w)$ is characterized by the following inequality:

$$
\left\langle w-P_{S}(w), x-P_{S}(w)\right\rangle \leq 0, \quad \forall x \in S,
$$

and $P_{S}$ is nonexpansive and averaged.

We now collect some elementary facts which will be used in the proofs of our main results.

Lemma 1 (see $[11,12])$. Let $X$ be a Banach space, $C$ a closed convex subset of $X$, and $T: C \rightarrow C$ a nonexpansive mapping with $\operatorname{Fix}(T) \neq \emptyset$. If $\left\{x_{n}\right\}$ is a sequence in $C$ weakly converging to $x$ and if $\left\{(I-T) x_{n}\right\}$ converges strongly to $y$, then $(I-T) x=y$.

Lemma 2 (see [13]). Let $H$ be a Hilbert space and $\left\{w_{n}\right\}$ a sequence in $H$ such that there exists a nonempty set $S \subseteq H$ satisfying the following.

(i) For every $w \in S, \lim _{n \rightarrow \infty}\left\|w_{n}-w\right\|$ exists.

(ii) Any weak-cluster point of the sequence $\left\{w_{n}\right\}$ belongs to $S$. $\widetilde{w}$.

Then, there exists $\widetilde{w} \in$ s such that $\left\{w_{n}\right\}$ weakly converges to

Lemma 3 (see [4]). Let $A$ and $B$ be averaged operators and suppose that $\operatorname{Fix}(A) \cap \operatorname{Fix}(B)$ is nonempty. Then $\operatorname{Fix}(A) \cap$ $\operatorname{Fix}(B)=\operatorname{Fix}(A B)=\operatorname{Fix}(B A)$.
The following lemma is vital in our main results.

Lemma 4. Let $T=I-\gamma G^{*} G$, where $0<\gamma<\lambda=$ $2 / \rho\left(G^{*} G\right)$ with $\rho\left(G^{*} G\right)$ being the spectral radius of the selfadjoint operator $G^{*} G$ on $H$. Then we have the following:

(1) $\|T\| \leq 1$ (i.e., $T$ is nonexpansive) and averaged;

(2) $\operatorname{Fix}(T)=\{(x, y) \in H, A x=B y\}, \operatorname{Fix}\left(P_{S} T\right)=\operatorname{Fix}\left(P_{S}\right) \cap$ $\operatorname{Fix}(T)=\Gamma$

(3) $w \in \operatorname{Fix}\left(P_{S} T\right)$ if and only if $w$ is a solution of the variational inequality $\left\langle G^{*} G w, v-w\right\rangle \geq 0$, for all $v \in S$.

Proof. (1) It is easily proved that $\|T\| \leq 1$; we only prove that $T=I-\gamma G^{*} G$ is averaged. Indeed, choose $0<\beta<1$, such that $\gamma /(1-\beta)<2 / \rho\left(G^{*} G\right)$; then $T=I-\gamma G^{*} G=\beta I+(1-\beta) V$, where $V=I-\gamma /(1-\beta) G^{*} G$ is a nonexpansive mapping. That is to say, $T$ is averaged.

(2) If $w \in\{(x, y) \in H, A x=B y\}$, it is obvious that $w \in$ $\operatorname{Fix}(T)$. Conversely, assuming that $w \in \operatorname{Fix}(T)$, we have $w=$ $w-\gamma G^{*} G w$. Hence $\gamma G^{*} G w=0$; then $\|G w\|^{2}=\left\langle G^{*} G w, w\right\rangle=$ 0 ; we get that $w \in\{(x, y) \in H, A x=B y\}$. It follows $\operatorname{Fix}(T)=$ $\{(x, y) \in H, A x=B y\}$.

Now we prove $\operatorname{Fix}\left(P_{S} T\right)=\operatorname{Fix}\left(P_{S}\right) \cap \operatorname{Fix}(T)=\Gamma$. By $\operatorname{Fix}(T)=\{(x, y) \in H, A x=B y\}, \operatorname{Fix}\left(P_{S}\right) \cap \operatorname{Fix}(T)=\Gamma$ is obvious. On the other hand, since $\operatorname{Fix}\left(P_{S}\right) \cap \operatorname{Fix}(T)=\Gamma \neq \emptyset$, and both $P_{S}$ and $T$ are averaged, from Lemma 3, we have $\operatorname{Fix}\left(P_{S} T\right)=\operatorname{Fix}\left(P_{S}\right) \cap \operatorname{Fix}(T)$.

(3) Consider

$$
\begin{aligned}
\left\langle G^{*} G w, v-w\right\rangle & \geq 0, \quad \forall v \in S \\
& \Longleftrightarrow\left\langle w-\left(w-\gamma G^{*} G w\right), v-w\right\rangle \\
& \geq 0, \quad \forall v \in S \\
& \Longleftrightarrow w=P_{S}\left(w-\gamma G^{*} G w\right) \\
& \Longleftrightarrow w \in \operatorname{Fix}\left(P_{S} T\right) .
\end{aligned}
$$

\section{Iterative Algorithm for SEP}

In this section, we establish an iterative algorithm that converges weakly to a solution of SEP.

Algorithm 5. Choose an arbitrary initial point $w_{0}=\left(x_{0}, y_{0}\right)$, and sequence $\left\{w_{n}=\left(x_{n}, y_{n}\right)\right\}$ is generated by the following iteration:

$$
w_{n+1}=\left(1-\alpha_{n}\right)\left(I-\gamma G^{*} G\right) w_{n}+\alpha_{n} P_{S}\left(I-\gamma G^{*} G\right) w_{n},
$$

where $\alpha_{n} \subseteq(0,1)$ and $0<\gamma<\lambda=2 / \rho\left(G^{*} G\right)$ with $\rho\left(G^{*} G\right)$ being the spectral radius of the self-adjoint operator $G^{*} G$ on $H$.

To prove its convergence we need the following lemma.

Lemma 6. The sequence $\left\{w_{n}\right\}$ generated by algorithm (10) is Féjer-monotone with respect to $\Gamma$; that is to say, for every $w \in \Gamma$,

$$
\left\|w_{n+1}-w\right\| \leq\left\|w_{n}-w\right\|, \quad \forall n \geq 1,
$$

if $\left\{\alpha_{n}\right\} \subseteq(0,1)$ and $0<\gamma<\lambda=2 / \rho\left(G^{*} G\right)$. 
Proof. Let $u_{n}=\left(I-\gamma G^{*} G\right) w_{n}$ and choose $w \in \Gamma$; by Lemma 4, $w \in \operatorname{Fix}\left(P_{S}\right) \cap \operatorname{Fix}\left(I-\gamma G^{*} G\right), G w=0$ and we have

$$
\begin{aligned}
\| w_{n+1}- & w \|^{2} \\
= & \left\|\left(1-\alpha_{n}\right) u_{n}+\alpha_{n} P_{S}\left(u_{n}\right)-w\right\|^{2} \\
\leq & \left(1-\alpha_{n}\right)\left\|u_{n}-w\right\|^{2}+\alpha_{n}\left\|P_{S}\left(u_{n}\right)-w\right\|^{2} \\
& -\alpha_{n}\left(1-\alpha_{n}\right)\left\|u_{n}-P_{S}\left(u_{n}\right)\right\|^{2} \\
\leq & \left(1-\alpha_{n}\right)\left\|u_{n}-w\right\|^{2}+\alpha_{n}\left\|u_{n}-w\right\|^{2} \\
& -\alpha_{n}\left(1-\alpha_{n}\right)\left\|u_{n}-P_{S}\left(u_{n}\right)\right\|^{2} \\
= & \left\|u_{n}-w\right\|^{2}-\alpha_{n}\left(1-\alpha_{n}\right)\left\|u_{n}-P_{S}\left(u_{n}\right)\right\|^{2} .
\end{aligned}
$$

Moreover, we have

$$
\begin{aligned}
\left\|u_{n}-w\right\|^{2}= & \left\|\left(I-\gamma G^{*} G\right) w_{n}-w\right\|^{2} \\
= & \left\|w_{n}-w\right\|^{2}+\left\|\gamma G^{*} G w_{n}\right\|^{2} \\
& -2\left\langle w_{n}-w, \gamma G^{*} G w_{n}\right\rangle \\
= & \left\|w_{n}-w\right\|^{2}+\gamma^{2}\left\langle G w_{n}, G G^{*} G w_{n}\right\rangle \\
& -2 \gamma\left\langle G w_{n}-G w, G w_{n}\right\rangle \\
\leq & \left\|w_{n}-w\right\|^{2}+\gamma^{2} \lambda\left\|G w_{n}\right\|^{2} \\
& -2 \gamma\left\langle G w_{n}-0, G w_{n}\right\rangle \\
= & \left\|w_{n}-w\right\|^{2}-\gamma(2-\lambda \gamma)\left\|G w_{n}\right\|^{2} .
\end{aligned}
$$

Hence, we can get that

$$
\begin{aligned}
\left\|w_{n+1}-w\right\|^{2} \leq & \left\|w_{n}-w\right\|^{2}-\alpha_{n}\left(1-\alpha_{n}\right)\left\|u_{n}-P_{S}\left(u_{n}\right)\right\|^{2} \\
& -\gamma(2-\lambda \gamma)\left\|G w_{n}\right\|^{2} .
\end{aligned}
$$

It follows that $\left\|w_{n+1}-w\right\| \leq\left\|w_{n}-w\right\|$, for all $w \in \Gamma, n \geq 1$.

Theorem 7. If $0<\liminf _{n \rightarrow \infty} \alpha_{n} \leq \limsup _{n \rightarrow \infty} \alpha_{n}<1$, then the sequence $\left\{w_{n}\right\}$ generated by algorithm (10) converges weakly to a solution of SEP (2).

Proof. Let $w$ be a solution of SEP; according to Lemma 6, we can get that the sequence $\left\|w_{n}-w\right\|$ is monotonically decreasing and converges to some positive real. Since $0<$ $\liminf _{n \rightarrow \infty} \alpha_{n} \leq \limsup _{n \rightarrow \infty} \alpha_{n}<1$ and $0<\gamma<\lambda$, by (14), we have

$$
\left\|u_{n}-P_{S}\left(u_{n}\right)\right\| \longrightarrow 0, \quad\left\|G w_{n}\right\| \longrightarrow 0, \quad \text { when } n \longrightarrow \infty \text {. }
$$

Since $\left\{w_{n}\right\}$ is Féjer-monotonicity, it follows that $\left\{w_{n}\right\}$ is bounded. Let $\widetilde{w}$ be a weak-cluster point of $\left\{w_{n}\right\}$ and let $k=$ $1,2, \ldots$ be the sequence of indices, such that $w_{n_{k}}$ converges weakly to $\widetilde{w}$. By Lemma 1, we can get that $G \widetilde{w}=0$. It follows that $\widetilde{w} \in \operatorname{Fix}\left(I-\gamma G^{*} G\right)$.
Since $u_{n}=\left(I-\gamma G^{*} G\right) w_{n}$, it follows that $u_{n_{k}}$ converges weakly to $\widetilde{w}$. On the other hand, $\left\|u_{n}-P_{S}\left(u_{n}\right)\right\| \rightarrow 0$. Using Lemma 1 again, we obtain that $P_{S}(\widetilde{w})=\widetilde{w}$. That is to say, $\widetilde{w} \in$ $\operatorname{Fix}\left(P_{S}\right)$

Hence $\widetilde{w} \in \operatorname{Fix}\left(P_{S}\right) \cap \operatorname{Fix}\left(I-\gamma G^{*} G\right)$. By Lemma 4, we get that $\widetilde{w}$ is a solution of $\operatorname{SEP}(2)$.

The weak convergence of the whole sequence $\left\{w_{n}\right\}$ holds true since all conditions of the well-known Opial's lemma (Lemma 2) are fulfilled with $S=\Gamma$.

\section{Iterative Algorithm for MSSEP}

In this section, we establish an iterative algorithm that converges weakly to a solution of MSSEP.

We use $\bar{\Gamma}$ to denote the solution set of MSSEP, that is,

$$
\bar{\Gamma}=\left\{(x, y) \in H_{1} \times H_{2}, A x=B y, x \in \bigcap_{i=1}^{N} C_{i}, y \in \bigcap_{j=1}^{M} Q_{j}\right\},
$$

and assume consistency of MSSEP so that $\bar{\Gamma}$ is closed, convex, and nonempty.

Without loss of generality, we assume that $N=M$. In fact, if $N>M$, let $Q_{j}=H_{2}$, for $j>M$.

Let $S_{i}=C_{i} \times Q_{i}$ in $H=H_{1} \times H_{2}$ and define $G: H \rightarrow H_{3}$ by $G=[A,-B]$; then $G^{*} G: H \rightarrow H$ has the following matrix form:

$$
G^{*} G=\left[\begin{array}{cc}
A^{*} A & -A^{*} B \\
-B^{*} A & B^{*} B
\end{array}\right]
$$

The original problem now can be reformulated as finding $w=$ $(x, y) \in \cap_{i=1}^{N} S_{i}$ with $G w=0$, or, more generally, minimizing the function $\|G w\|$ over $w \in \cap_{i=1}^{N} S_{i}$.

Algorithm 8. For an arbitrary initial point $w_{0}=\left(x_{0}, y_{0}\right)$, sequence $\left\{w_{n}=\left(x_{n}, y_{n}\right)\right\}$ is generated by the following iteration:

$$
w_{n+1}=\left(1-\alpha_{n}\right)\left(I-\gamma G^{*} G\right) w_{n}+\alpha_{n} P_{S_{i(n)}}\left(I-\gamma G^{*} G\right) w_{n},
$$

where $i(n)=n(\bmod N)+1, \alpha_{n}>0$ is a sequence in $(0,1)$, and $0<\gamma<\lambda=2 / \rho\left(G^{*} G\right)$ with $\rho\left(G^{*} G\right)$ being the spectral radius of the self-adjoint operator $G^{*} G$ on $H$.

The proof of the following lemma is similar to Lemma 4, and we omit its proof.

Lemma 9. Let $T=I-\gamma G^{*} G$, where $0<\gamma<\lambda=$ $2 / \rho\left(G^{*} G\right)$ with $\rho\left(G^{*} G\right)$ being the spectral radius of the selfadjoint operator $G^{*} G$ on $H$. Then we have $\operatorname{Fix}(T)=\{(x, y) \epsilon$ $H, A x=B y\}, \operatorname{Fix}\left(P_{\cap S_{i}} T\right)=\operatorname{Fix}\left(P_{\cap S_{i}}\right) \cap \operatorname{Fix}(T)=\bar{\Gamma}$, and $\cap \operatorname{Fix}\left(P_{S_{i}} T\right)=\cap\left[\operatorname{Fix}\left(P_{S_{i}}\right) \cap \operatorname{Fix}(T)\right]=\bar{\Gamma}$. lemma.

To prove its convergence we also need the following 
Lemma 10. Any sequence $\left\{w_{n}\right\}$ generated by algorithm (18) is the Féjer-monotone with respect to $\bar{\Gamma}$; namely, for every $w \in \bar{\Gamma}$,

$$
\left\|w_{n+1}-w\right\| \leq\left\|w_{n}-w\right\|, \quad \forall n \geq 1,
$$

provided that $\alpha_{n}>0$ is a sequence in $(0,1)$ and $0<\gamma<\lambda=$ $2 / \rho\left(G^{*} G\right)$.

Proof. Let $u_{n}=\left(I-\gamma G^{*} G\right) w_{n}$ and take $w \in \bar{\Gamma}$; by Lemma 9, $w \in \operatorname{Fix}\left(P_{S_{i}}\right) \cap \operatorname{Fix}\left(I-\gamma G^{*} G\right)$, for all $N \geq i \geq 1, G w=0$ and we have

$$
\begin{aligned}
\left\|w_{n+1}-w\right\|^{2}= & \left\|\left(1-\alpha_{n}\right) u_{n}+\alpha_{n} P_{S_{i(n)}}\left(u_{n}\right)-w\right\|^{2} \\
\leq & \left(1-\alpha_{n}\right)\left\|u_{n}-w\right\|^{2}+\alpha_{n}\left\|P_{S_{i(n)}}\left(u_{n}\right)-w\right\|^{2} \\
& -\alpha_{n}\left(1-\alpha_{n}\right)\left\|u_{n}-P_{S_{i(n)}}\left(u_{n}\right)\right\|^{2} \\
\leq & \left(1-\alpha_{n}\right)\left\|u_{n}-w\right\|^{2}+\alpha_{n}\left\|u_{n}-w\right\|^{2} \\
& -\alpha_{n}\left(1-\alpha_{n}\right)\left\|u_{n}-P_{S_{i(n)}}\left(u_{n}\right)\right\|^{2} \\
= & \left\|u_{n}-w\right\|^{2}-\alpha_{n}\left(1-\alpha_{n}\right)\left\|u_{n}-P_{S_{i(n)}}\left(u_{n}\right)\right\|^{2} .
\end{aligned}
$$

Moreover, all the same to the proof of Lemma 6, we have

$$
\left\|u_{n}-w\right\|^{2} \leq\left\|w_{n}-w\right\|^{2}-\gamma(2-\lambda \gamma)\left\|G w_{n}\right\|^{2} .
$$

Hence, we have

$$
\begin{aligned}
\left\|w_{n+1}-w\right\|^{2} \leq & \left\|w_{n}-w\right\|^{2}-\alpha_{n}\left(1-\alpha_{n}\right)\left\|u_{n}-P_{S_{i(n)}}\left(u_{n}\right)\right\|^{2} \\
& -\gamma(2-\lambda \gamma)\left\|G w_{n}\right\|^{2} .
\end{aligned}
$$

It follows that $\left\|w_{n+1}-w\right\| \leq\left\|w_{n}-w\right\|$, for all $w \in \bar{\Gamma}, n \geq 1$.

Theorem 11. If $0<\liminf _{n \rightarrow \infty} \alpha_{n} \leq \limsup _{n \rightarrow \infty} \alpha_{n}<1$, then the sequence $\left\{w_{n}\right\}$ generated by algorithm (18) converges weakly to a solution of MSSEP (3).

Proof. From (22) and the fact that $0<\liminf _{n \rightarrow \infty} \alpha_{n} \leq$ $\limsup _{n \rightarrow \infty} \alpha_{n}<1$ and $0<\gamma<\lambda=2 / \rho\left(G^{*} G\right)$, we obtain that

$$
\sum_{n=0}^{\infty}\left\|u_{n}-P_{S_{i(n)}}\left(u_{n}\right)\right\|^{2}<\infty, \quad \sum_{n=0}^{\infty}\left\|G w_{n}\right\|^{2}<\infty .
$$

Therefore,

$$
\lim _{n \rightarrow \infty}\left\|u_{n}-P_{S_{i(n)}}\left(u_{n}\right)\right\|=0, \quad \lim _{n \rightarrow \infty}\left\|G w_{n}\right\|=0 .
$$

Since $\left\{w_{n}\right\}$ is Féjer-monotone, it follows that $\left\{w_{n}\right\}$ is bounded. Let $\widetilde{w}$ be a weak-cluster point of $\left\{w_{n}\right\}$. Taking a subsequence $\left\{w_{n_{k}}\right\}$ of $\left\{w_{n}\right\}$ such that $w_{n_{k}}$ converges weakly to $\widetilde{w}$, then, by Lemma 1 , we can get that $G \widetilde{w}=0$; it follows that $\widetilde{w} \in \operatorname{Fix}\left(I-\gamma G^{*} G\right)$.
Let $u_{n}=\left(I-\gamma G^{*} G\right) w_{n}$; it follows that $u_{n_{k}}$ converges weakly to $\widetilde{w}$.

Since

$$
\begin{aligned}
\| w_{n+1} & -w_{n} \|^{2} \\
& =\left\|\left(1-\alpha_{n}\right) u_{n}+\alpha_{n} P_{S_{i(n)}}\left(u_{n}\right)-w_{n}\right\|^{2} \\
& =\left\|\alpha_{n}\left(P_{S_{i(n)}} u_{n}-u_{n}\right)+u_{n}-w_{n}\right\|^{2} \\
& \leq 2 \alpha_{n}^{2}\left\|\left(P_{S_{i(n)}} u_{n}-u_{n}\right)\right\|^{2}+2\left\|\gamma G^{*} G w_{n}\right\|^{2} \\
& =2 \alpha_{n}^{2}\left\|\left(P_{S_{i(n)}} u_{n}-u_{n}\right)\right\|^{2}+2 \gamma^{2}\left\langle G w_{n}, G G^{*} G w_{n}\right\rangle \\
& \leq 2 \alpha_{n}^{2}\left\|\left(P_{S_{i(n)}} u_{n}-u_{n}\right)\right\|^{2}+2 \gamma^{2} \lambda\left\|G w_{n}\right\|^{2},
\end{aligned}
$$

it follows that

$$
\sum_{n=0}^{\infty}\left\|w_{n+1}-w_{n}\right\|^{2}<\infty
$$

On the other hand

$$
\begin{aligned}
\| u_{n+1} & -u_{n} \|^{2} \\
& =\left\|w_{n+1}-w_{n}+\gamma G^{*} G\left(w_{n+1}-w_{n}\right)\right\|^{2} \\
& \leq 2\left(\left\|w_{n+1}-w_{n}\right\|^{2}+\left\|\gamma G^{*} G\left(w_{n+1}-w_{n}\right)\right\|^{2}\right) \\
& \leq 2\left(\left\|w_{n+1}-w_{n}\right\|^{2}+\gamma^{2} \lambda\left\|\left(w_{n+1}-w_{n}\right)\right\|^{2}\right) .
\end{aligned}
$$

Hence

$$
\sum_{n=0}^{\infty}\left\|u_{n+1}-u_{n}\right\|^{2}<\infty .
$$

We can get that $\lim _{n \rightarrow \infty}\left\|u_{n+1}-u_{n}\right\|=0$ and $\lim _{n \rightarrow \infty} \| u_{n+j}-$ $u_{n} \|=0$ for all $j=1,2, \ldots, N$.

Moreover, for any $i=1,2, \ldots, N$,

$$
\begin{aligned}
\left\|u_{n}-P_{S_{n+i}} u_{n}\right\| \leq & \left\|u_{n}-u_{n+i}\right\|+\left\|u_{n+i}-P_{S_{n+i}} u_{n+i}\right\| \\
& +\left\|P_{S_{n+i}} u_{n+i}-P_{S_{n+i}} u_{n}\right\| \\
\leq & 2\left\|u_{n}-u_{n+i}\right\|+\left\|u_{n+i}-P_{S_{n+i}} u_{n+i}\right\| \\
& \longrightarrow 0 .
\end{aligned}
$$

Thus, $\lim _{n \rightarrow \infty}\left\|u_{n}-P_{S_{i}} u_{n}\right\|=0$ for all $i=1,2, \ldots, N$. Using Lemma 1 again, we obtain that $P_{S_{i}}(\widetilde{w})=\widetilde{w}$. That is to say, $\widetilde{w} \in$ $\operatorname{Fix}\left(P_{S_{i}}\right)$ for all $i=1,2, \ldots, N$.

Hence $\widetilde{w} \in \cap \operatorname{Fix}\left(P_{S_{i}}\right) \cap \operatorname{Fix}\left(I-\gamma G^{*} G\right)$. By Lemma 9, we obtain that $\widetilde{w}$ is a solution of MSSEP (3).

The weak convergence of the whole sequence $\left\{w_{n}\right\}$ holds true since all conditions of the well-known Opial's lemma (Lemma 2) are fulfilled with $S=\bar{\Gamma}$.

\section{Conflict of Interests}

The authors declare that there is no conflict of interests regarding the publication of this paper. 


\section{Acknowledgment}

This research was supported by NSFC Grants no. 11071279; no. 11226125; and no. 11301379 .

\section{References}

[1] Y. Censor and T. Elfving, "A multiprojection algorithm using Bregman projections in a product space," Numerical Algorithms, vol. 8, no. 2-4, pp. 221-239, 1994.

[2] Y. Censor, T. Elfving, N. Kopf, and T. Bortfeld, “The multiplesets split feasibility problem and its applications for inverse problems," Inverse Problems, vol. 21, no. 6, pp. 2071-2084, 2005.

[3] C. Byrne, "Iterative oblique projection onto convex sets and the split feasibility problem," Inverse Problems, vol. 18, no. 2, pp. 441453, 2002.

[4] C. Byrne, "A unified treatment of some iterative algorithms in signal processing and image reconstruction," Inverse Problems, vol. 20, no. 1, pp. 103-120, 2004.

[5] B. Qu and N. Xiu, "A note on the CQ algorithm for the split feasibility problem," Inverse Problems, vol. 21, no. 5, pp. 1655$1665,2005$.

[6] H.-K. Xu, "A variable Krasnosel'skii-Mann algorithm and the multiple-set split feasibility problem," Inverse Problems, vol. 22, no. 6, pp. 2021-2034, 2006.

[7] Q. Yang, "The relaxed CQ algorithm solving the split feasibility problem," Inverse Problems, vol. 20, no. 4, pp. 1261-1266, 2004.

[8] Q. Yang and J. Zhao, "Generalized KM theorems and their applications," Inverse Problems, vol. 22, no. 3, pp. 833-844, 2006.

[9] A. Moudafi, "A relaxed alternating CQ-algorithm for convex feasibility problems," Nonlinear Analysis: Theory, Methods \& Applications, vol. 79, pp. 117-121, 2013.

[10] L. Y. Shi, R. D. Chen, and Y. J. Wu, "Strong convergence of iterative algorithms for the split equality problem," Inverse Problems. In press.

[11] K. Goebel and W. A. Kirk, Topics in Metric Fixed Point Theory, vol. 28 of Cambridge Studies in Advanced Mathematics, Cambridge University Press, Cambridge, UK, 1990.

[12] K. Geobel and S. Reich, Uniform Convexity, Nonexpansive Mappings, and Hyperbolic Geometry, Dekker, 1984.

[13] F. Schöpfer, T. Schuster, and A. K. Louis, "An iterative regularization method for the solution of the split feasibility problem in Banach spaces," Inverse Problems, vol. 24, no. 5, pp. 055008055027, 2008. 


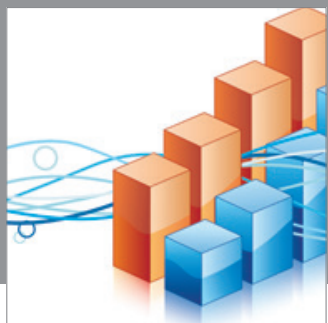

Advances in

Operations Research

mansans

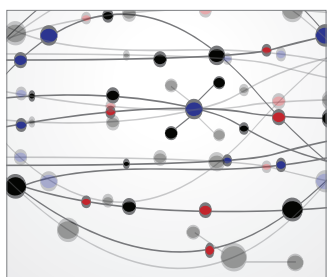

The Scientific World Journal
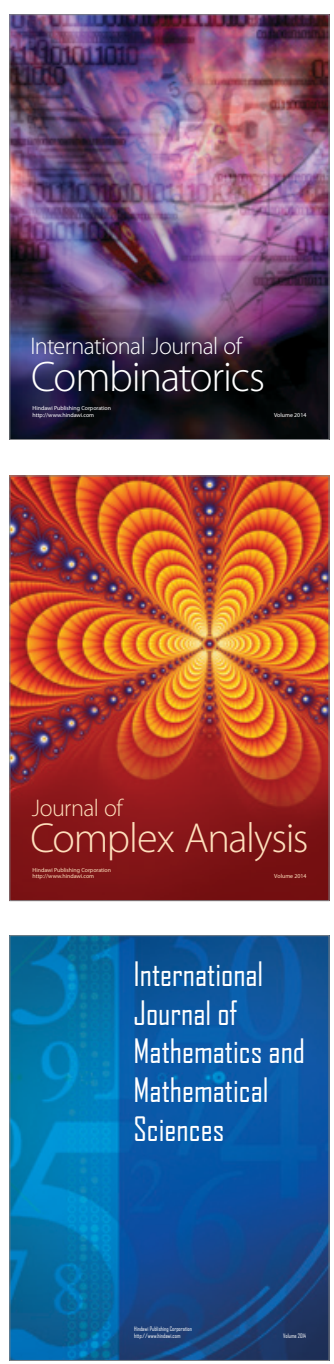
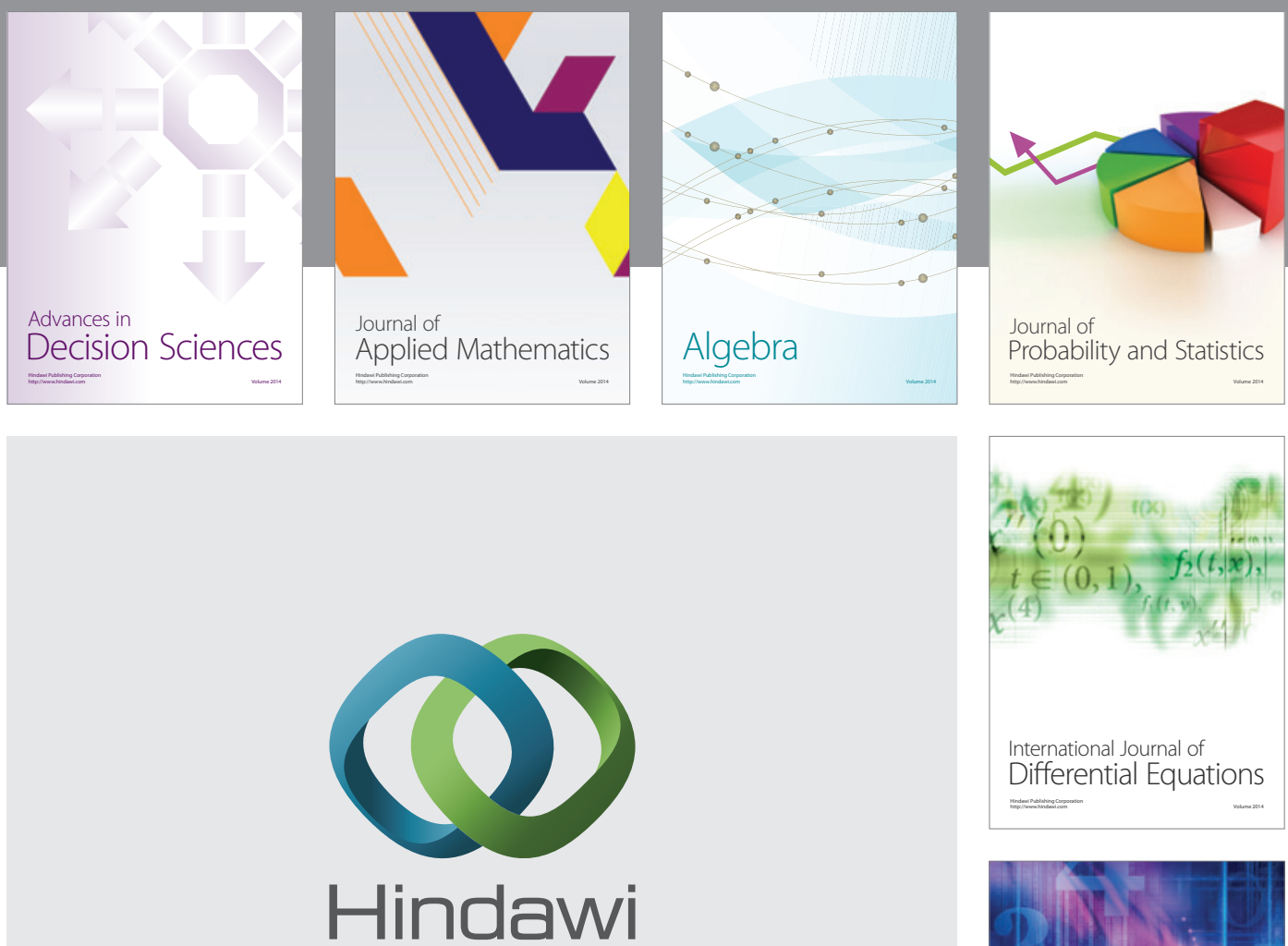

Submit your manuscripts at http://www.hindawi.com
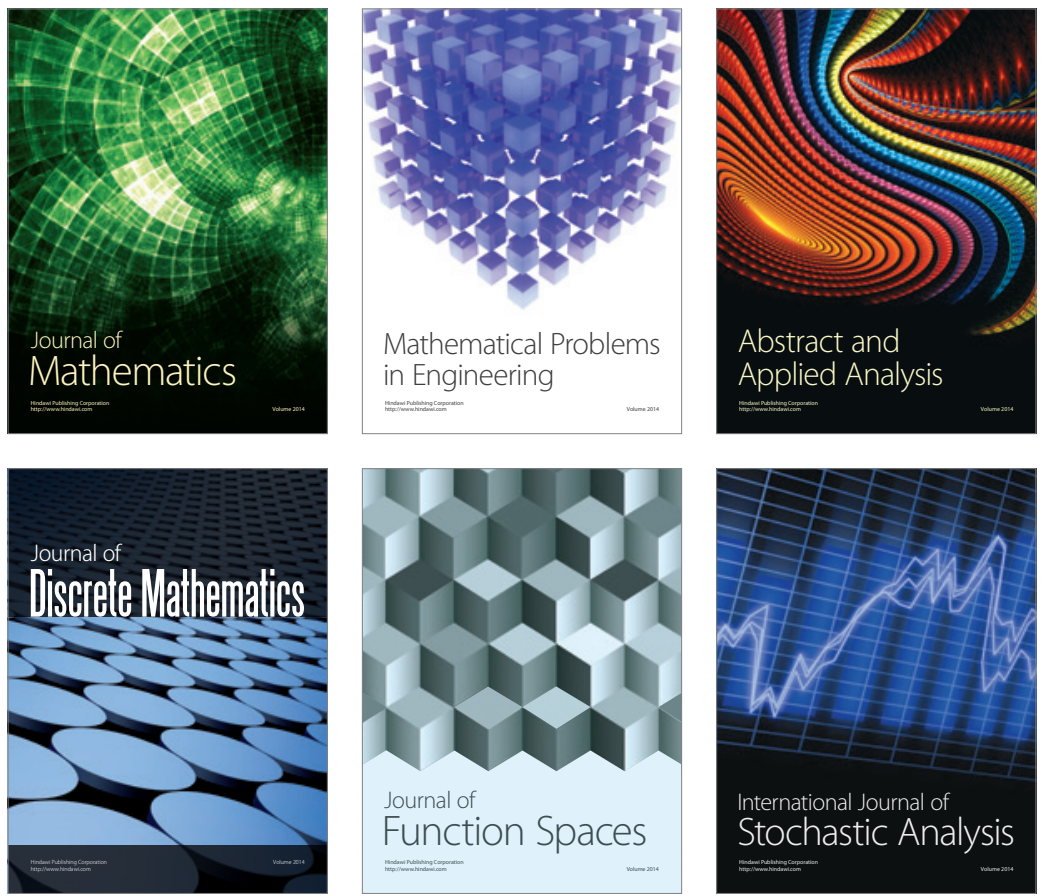

Journal of

Function Spaces

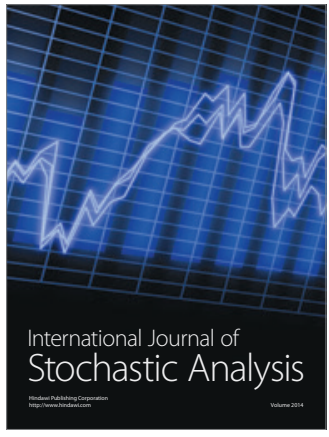

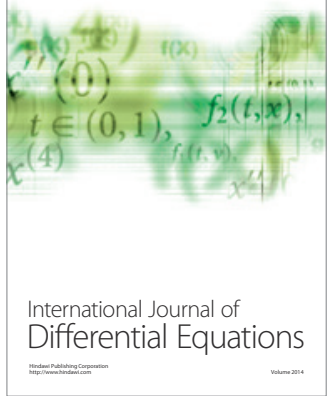
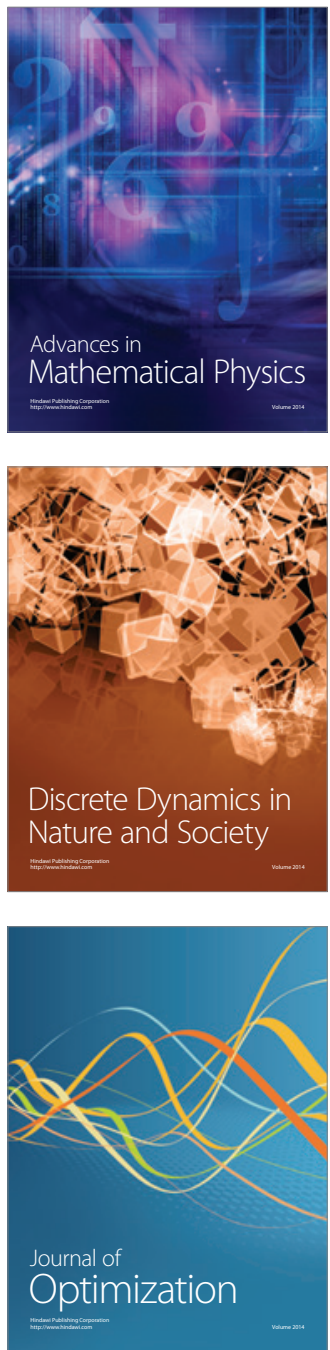